\title{
Article
}

\section{The Italian Twin Registry: An Update at 18 Years From Its Inception}

\author{
Emanuela Medda, Virgilia Toccaceli, Corrado Fagnani, Lorenza Nisticò, Sonia Brescianini, Miriam Salemi, Maurizio Ferri, \\ Cristina D’Ippolito, Sabrina Alviti, Antonio Arnofi and Maria Antonietta Stazi \\ Reference Centre for Behavioural Sciences and Mental Health, Istituto Superiore di Sanità, Rome, Italy
}

\begin{abstract}
The Italian Twin Registry (ITR), established in 2001, is a population-based registry of voluntary twins. To date, it consists of approximately 29,000 twins who gave their consent to participate in the studies proposed by the ITR research group. The database comprises 11,500 monozygotic and 16,700 dizygotic twins resident throughout the country and belonging to a wide age range (from 0 to 95 years, mean 36.8 years). This article provides an overview of the recruitment strategies along with the major phenotypes investigated during an 18 years' research period. Over the years, several self-reported questionnaire data were collected, together with saliva/blood samples and measurements taken during in-person interviews or outpatient clinical examinations. Mental and behavioral phenotypes as well as atherosclerotic traits were studied in depth across different age groups. A birth cohort of twins was established and followed up. Novel research hypotheses are also being tested in ongoing projects. The ITR is involved in international studies in collaboration with other twin registries and represents a valuable resource for national and international research initiatives regarding a broad spectrum of health-related characteristics.
\end{abstract}

Keywords: Twin register; mental health; Italian twins; biobanking; environment; genetics; twin studies

(Received 31 May 2019; accepted 1 July 2019; First Published online 26 September 2019)

The birth of the Italian Twin Registry (ITR) dates back to the year 2001 when a broad project of the Italian Ministry of Health supported and funded its implementation at the Italian National Institute of Health (Istituto Superiore di Sanità). At the very beginning, the ITR database consisted of a list of 'possible twin pairs' identified by the Ministry of Finance using the demographic information summarized in the fiscal code, a sort of personal identifier used by the tax system. That database, containing 650,000 'possible twin pairs' with the same surname, date and place of birth and born before the end of 1996 (Stazi et al., 2002), allowed us to perform the first Italian population-based twin studies on celiac disease (Greco et al., 2002), multiple sclerosis (Ristori et al., 2006) and type 1 diabetes (Nisticò et al., 2012).

The 'possible twin pairs' database was used until 2003 when other approaches for twin pairs recruitment were adopted. Currently, a total of 29,000 twins are enrolled in the ITR.

Most of the twins are recruited by applying a population-based strategy in several municipalities. Twins are selected among the residents according to the following criteria: same mother and father, same date and place of birth. To these twins, a letter is sent explaining the aims and the enrollment procedures of the ITR. Between 2009 and 2014, a new recruitment strategy was introduced: a cohort of twins was enrolled at birth in eight hospitals located in different Italian regions with the aim of studying pediatric and adult

Author for correspondence: Emanuela Medda, Email: emanuela.medda@iss.it Cite this article: Medda E, Toccaceli V, Fagnani C, Nisticò L, Brescianini S, Salemi M, Ferri M, D'Ippolito C, Alviti S, Arnofi A, and Stazi MA. (2019) The Italian Twin Registry: An Update at 18 Years From Its Inception. Twin Research and Human Genetics 22: 572-578, https://doi.org/10.1017/thg.2019.75 outcomes (MUltiple BIrth COhort Study, MUBICOS). As a final strategy, various sensitization actions were put in place to inform the medical community and the general public on the research activities carried out by the ITR. As a result, several twins voluntarily asked for taking part in the Registry.

At the time of enrollment, adult twins (aged 18 years and over) complete a questionnaire on socio-demographic characteristics and give their written consent to be contacted for future research projects proposed by the ITR. Parents of underage twins sign an informed consent form to allow their children to participate in the ITR and fill in the demographic questionnaire on their behalf. The basic characteristics of twins enrolled in the ITR are reported in Table 1. The emerging differences in twin distribution by geographical area ( $48 \%$ of the twins live in the north of Italy, while $19 \%$ live in the south) and age group are explained by the adopted inclusion criteria, which are usually study-, age- and region-specific.

Table 2 summarizes the total number of twins recruited by age, zygosity and gender, and shows that the ITR includes a wide range of age groups from newborns to the elderly.

Different phenotypes have been investigated by the ITR since its inception 18 years ago, and data collection strategies vary according to study design and research aims (Brescianini et al., 2013; Fagnani et al., 2006). In particular, for most studies, information is obtained using self-administered standardized questionnaires through regular mail. Recently, in order to facilitate and speed up the answering procedure and data acquisition, a web-based platform was implemented. In specific studies regarding outpatients' examinations, health information and clinical measurements are collected by trained physicians in selected hospitals.

(c) The Author(s) 2019. This is an Open Access article, distributed under the terms of the Creative Commons Attribution-NonCommercial-ShareAlike licence (http://creativecommons. org/licenses/by-nc-sa/4.0/), which permits non-commercial re-use, distribution, and reproduction in any medium, provided the same Creative Commons licence is included and the original work is properly cited. The written permission of Cambridge University Press must be obtained for commercial re-use. 
Table 1. Basic characteristics of twins enrolled in the ITR

\begin{tabular}{|c|c|c|}
\hline & Children $N=11,376$ & Adults $N=17,970$ \\
\hline Information at enrollment & $N(\%)$ & $N(\%)$ \\
\hline \multicolumn{3}{|l|}{ Age at enrollment, years } \\
\hline Range & $0-17$ & $18-96$ \\
\hline Mean $\pm S D$ & $7.7 \pm 5.2$ & $36.8 \pm 18.5$ \\
\hline \multicolumn{3}{|l|}{ Gender } \\
\hline Male & $5740(50.5 \%)$ & 7719 (43.0\%) \\
\hline Female & $5636(49.5 \%)$ & $10,251(57.0 \%)$ \\
\hline \multicolumn{3}{|l|}{ Area of residence } \\
\hline North & $6293(55.5 \%)$ & $7794(43.5 \%)$ \\
\hline Center & $3619(31.9 \%)$ & $5969(33.3 \%)$ \\
\hline South & $1431(12.6 \%)$ & $4171(23.2 \%)$ \\
\hline \multicolumn{3}{|l|}{ Educational level } \\
\hline Less than high school diploma & $11,376(100 \%)$ & $3752(21.8 \%)$ \\
\hline High school diploma & - & $10,262(59.7 \%)$ \\
\hline Degree or higher & - & $3171(18.5 \%)$ \\
\hline \multicolumn{3}{|l|}{ Employment status } \\
\hline Student & - & $1180(8.9 \%)$ \\
\hline Employed & - & $8867(67.2 \%)$ \\
\hline Unemployed & - & $1375(10.4 \%)$ \\
\hline Retired & - & $1770(13.4 \%)$ \\
\hline \multicolumn{3}{|l|}{ Marital status } \\
\hline Single/divorced & - & $10,299(62.2 \%)$ \\
\hline Married & - & $5854(35.4 \%)$ \\
\hline Widowed & - & $403(2.4 \%)$ \\
\hline \multicolumn{3}{|l|}{ Living together } \\
\hline Yes & $100 \%$ & $1765(16.2 \%)$ \\
\hline
\end{tabular}

Note: ITR, Italian Twin Registry; SD, standard deviation.

Over the years, the ITR has joined various consortia and collaborative projects, such as GenomEUtwin (Peltonen, 2003), Euroclot (Carter et al., 2007), GEHA (Nebel \& Schreiber, 2004) and CODATwins (Silventoinen et al., 2015). Furthermore, the ITR welcomes both national and international collaborations in order to find new opportunities for biomedical and epidemiological twin research.

\section{Zygosity Assessment and the ITR Biobank}

Twin zygosity is assigned using an algorithm based on the responses given by each pair (or the parents) about physical similarity and how frequently they were confused by family members and strangers during childhood (Goldsmith, 1991; Kyvik et al., 1995). However, when DNA is available, zygosity of the same-gender twin pairs is assessed by genetic testing. DNA-based zygosity is assigned using a set of nine tetranucleotide markers plus amelogenin for sex determination.

So far, the ITR has collected biological samples from 2150 twins and almost 900 twins' parents. Biological samples consist of DNA (extracted from saliva or saliva swab for $78 \%$ of twins and all twins' parents), peripheral blood and derivatives (lymphocytes, buffy coat, serum and plasma for $20 \%$ of twins) and dried blood spots on filter cards ( $2 \%$ of twins). Four percent of twins donated both saliva and blood. Saliva was self-collected at home, at 'Twin Days,' or during clinical examinations for specific research projects; saliva swabs were collected from children unable to spit, mainly from newborns at the hospitals involved in the MUBICOS study. Kits from DNA Genotek were used in both cases. Blood spots were collected from a subsample of newborn twins. Samples are stored in vapor nitrogen tanks or $-80^{\circ} \mathrm{C}$ freezers in the ITR biobank or in external service provider facilities. Donors signed an informed consent that authorizes a 20 years' storage period of their biological material. For under 18 years' old subjects, storage is allowed until full age, when consent must be newly requested. Approximately 700 twins, selected among those having detailed phenotypes, have been large-scale genotyped with arrays (>665,000 markers) enriched with disease and human traits variants.

\section{Major Findings and Ongoing Studies}

The ITR collects information on a large spectrum of phenotypes by either self-reported questionnaires or clinical examinations (Table 3). As data are collected across different studies, the number of informative twins varies for each trait or set of phenotypes.

\section{Multiple Births Cohort Study}

The MUBICOS cohort study has been described in a previous work (Brescianini et al., 2013). Since the establishment of the cohort, the twins underwent a focus on respiratory health and its relationship with growth in the first year of life. In detail, the association between growth in infancy and wheezing at 3 years of age is decomposed into genetic and environmental components using twin modelling techniques based on estimating between- and withinpair correlations (Brescianini et al., 2017). The next follow-up assessment will be at 10 years of age; besides general health status, it will focus on growth, neurocognitive development, physical activity and again respiratory health. As the little MUBICOS twin participants grow older, they will be increasingly involved in our research.

\section{From Children to Adults: Behavior, Personality and Brain Functioning}

In line with previous work, ITR behavioral genetics research has been focusing on childhood and adolescence. A sample of about 800 twins aged 14-17 years was recruited throughout Italy in a survey aimed at investigating the genetic and environmental bases of individual differences in emotion regulation and of the association between emotion regulation and quality of sleep. Emotion regulation was evaluated by the construct of Effortful Control (Fagnani et al., 2017), while sleep quality was assessed by the Sleep Disorders Questionnaire (Violani et al., 2004). At the same time, an additional independent sample of about 800 twins aged 8-17 years, previously recruited in the province of Milano and assessed for psychopathological and anxiety-related traits, has recently been re-evaluated to study the covariation between anxiety and anger behaviors. These two twin samples are currently being joined for an in-depth analysis of gender differences in internalizing and externalizing behavior, and in temperament-related problems including Novelty Seeking.

A close collaboration was established with the Universities of Milano, Udine and Verona, and with the Scientific Institute 'E. Medea' in Bosisio-Parini (Lecco) to implement a multidisciplinary 
Table 2. Number of twin subjects in the ITR by age group, zygosity and gender

\begin{tabular}{|c|c|c|c|c|c|c|c|c|}
\hline \multirow[b]{2}{*}{ Age group } & \multicolumn{2}{|c|}{$M Z$} & \multicolumn{2}{|c|}{ DZ same sex } & \multicolumn{2}{|c|}{ DZ opposite sex } & \multirow{2}{*}{$\begin{array}{l}\text { Unknown } \\
\text { zygosity }^{a}\end{array}$} & \multirow[b]{2}{*}{ Total } \\
\hline & Male & Female & Male & Female & Male & Female & & \\
\hline Under 6 & 148 & 164 & 198 & 174 & 124 & 118 & 70 & 996 \\
\hline $6-10$ & 232 & 206 & 202 & 202 & 180 & 180 & 47 & 1249 \\
\hline $11-17$ & 612 & 608 & 786 & 722 & 554 & 553 & 38 & 3873 \\
\hline $18-29$ & 940 & 956 & 943 & 977 & 674 & 676 & 79 & 5245 \\
\hline $30-39$ & 1389 & 2179 & 963 & 1299 & 985 & 1030 & 182 & 8027 \\
\hline $40-49$ & 501 & 803 & 299 & 450 & 304 & 325 & 84 & 2766 \\
\hline $50-59$ & 448 & 711 & 313 & 419 & 272 & 361 & 75 & 2599 \\
\hline $60-69$ & 316 & 437 & 220 & 308 & 233 & 270 & 59 & 1843 \\
\hline $70-79$ & 258 & 254 & 180 & 229 & 221 & 224 & 140 & 1506 \\
\hline Over 80 & 157 & 207 & 129 & 138 & 157 & 145 & 309 & 1242 \\
\hline Total & 5001 & 6525 & 4233 & 4918 & 3704 & 3882 & 1083 & 29,346 \\
\hline
\end{tabular}

Note: ITR, Italian Twin Registry; MZ, monozygotic; DZ, dizygotic; a Unclear zygosity or incomplete twin pairs.

Table 3. Overview of major phenotypes collected by the ITR

\begin{tabular}{|c|c|}
\hline Phenotypes & Brief description of measures \\
\hline \multicolumn{2}{|l|}{ Children/Adolescents } \\
\hline Zygosity & Questionnaire on physical similarity, DNA zygosity test \\
\hline Parents & $\begin{array}{l}\text { Parental educational level, occupation, maternal occupation exposure during pregnancy, parental age at twin birth, } \\
\text { spontaneous/iatrogenic pregnancy, family composition, residence address (latitude and longitude) }\end{array}$ \\
\hline $\begin{array}{l}\text { Anthropometric } \\
\text { characteristics }\end{array}$ & Height, weight, birth weight, gestational age at birth \\
\hline Health & $\begin{array}{l}\text { Prenatal and neonatal condition, growth information, asthma and allergies, migraine, breastfeeding, diet, active and passive } \\
\text { smoke, relevant diseases }\end{array}$ \\
\hline Sleep & Pittsburgh Sleep Quality Index (PSQI), Sleep Disorders Questionnaire (SDQ), co-sleeping \\
\hline Environmental exposure & Green-blue spaces, air pollutants (PM2.5, $\left.\mathrm{NO}_{2}\right)$ \\
\hline $\begin{array}{l}\text { Behavior/personality/social } \\
\text { attitude }\end{array}$ & $\begin{array}{l}\text { Emotion regulation, ADHD, behavioral problems, eating disorders, parent-report Child Behavior Checklist (CBCL), Youth } \\
\text { Self-Report Form (YSR); the Screen for Child Anxiety Related Disorders (SCARED); Rosenberg self-esteem Scale (RSES); } \\
\text { Satisfaction With Life Scale (SWLS); Subjective Happiness Scale (Lyubomirsky, S), Life orientation test (LOT), PPCL } \\
\text { (Parent Problem Checklist), Child neurodevelopment }\end{array}$ \\
\hline Neuroimaging & Structural and functional brain connectivity (DTI, fMRI) \\
\hline \multicolumn{2}{|l|}{ Adults } \\
\hline Zygosity & Questionnaire on physical similarity, DNA zygosity test \\
\hline Socio-demographic data & Educational level, employment, marital status, residence address (latitude and longitude), twinning recurrence \\
\hline $\begin{array}{l}\text { Anthropometric } \\
\text { measurements }\end{array}$ & Height, weight, waist/hip circumferences (self-reported or measured by trained physician), birth weight and gestational age \\
\hline Health & Medical history, main illnesses and prescribed medication, asthma, chronic pain, blood pressure, heart rate \\
\hline Environmental exposure & Green-blue spaces, air pollutants (PM2.5, $\left.\mathrm{NO}_{2}\right)$ \\
\hline Lifestyle and substance use & Smoke habits, alcohol use, caffeine intake, physical activity, diet and micronutrients (EPIC Food Frequency Questionnaire) \\
\hline Physical functioning & Grip strength \\
\hline Sleep & Sleep Disorders Questionnaire (SDQ) \\
\hline $\begin{array}{l}\text { Personality and mental } \\
\text { health }\end{array}$ & $\begin{array}{l}\text { Autistic traits, Development And Well-Being Assessment (DAWBA), Hypomanic Personality Scale (HPS), Magical Ideation Scale } \\
\text { (MIS), Perceptual Aberration Scale (PAS), Dyadic Adjustment Scale (DAS), Parent Problem Checklist (PPCL), Relationship } \\
\text { Quality Index (RQI), Life Events, Short Adjectives Checklist, Positivity Scale (P Scale), Rosenberg self-esteem scale (RSES), Life } \\
\text { orientation test (LOT), Ryff's Scales of Psychological Well-Being (PWB), Satisfaction with Life Scale (SWLS), Temperament and } \\
\text { Character Inventory (TCI-125), Attachment styles (ECR), Alexithymia (TAS-20) }\end{array}$ \\
\hline Prosocial Behavior & Empathy (EQ by Baron-Cohen), Attitude to donate biological sample (ITR validated questionnaire) \\
\hline
\end{tabular}


Table 3. (Continued)

\begin{tabular}{ll}
\hline Phenotypes & Brief description of measures \\
\hline Neuroimaging & Structural and functional brain connectivity (DTI, fMRI) \\
\hline Neurocognitive functioning & $\begin{array}{l}\text { Mini-Mental State Examination (MMSE), selective attention (Attentional Matrices), episodic long-term memory (Story Recall } \\
\text { test), non-verbal logical reasoning and problem-solving ability [Raven's Coloured Progressive Matrices (PM 36)], word } \\
\text { generation by phonological and semantic cues [Phonological (F-P-L) and Semantic (animals) Verbal Fluency test], auditory } \\
\text { comprehension of complex sentences (Token test), spatial abilities and constructional praxis (Copying Drawings) }\end{array}$ \\
\hline Atherosclerotic traits & $\begin{array}{l}\text { Measured blood pressure and heart rate, femoral and carotid Intima Media Thickness (IMT), Augmentation Index (AIX), Pulse } \\
\text { Wave Velocity (PWVao), plaques characteristics in femoral and carotid artery, cerebral arterial velocity and resistance }\end{array}$ \\
\hline Blood samples & $\begin{array}{l}\text { Ematochemical parameters, aluminum (Al), arsenic (As), cadmium (Cd), cobalt (Co), chromium (Cr), copper (Cu), mercury (Hg), } \\
\text { manganese (Mn), nickel (Ni), lead (Pb), selenium (Se), and zinc (Zn), OGG activity, non-enzymatic antioxidant capacity (NEAC) }\end{array}$ \\
\hline
\end{tabular}

approach to study gene-by-environment interaction in psychoses. In particular, more than 800 children, adolescent and young adult twins were recruited in Northern Italy and are still under evaluation for psychological and behavioral characteristics, and for genetic, epigenetic, immunological and cerebral markers. The psychological and behavioral evaluation was based on several validated scales, including Development And Well-Being Assessment (DAWBA), Hypomanic Personality Scale (HPS), Magical Ideation Scale (MIS), Perceptual Aberration Scale (PAS), Youth Self Report (YSR), Child Behavior Checklist (CBCL), Dyadic Adjustment Scale (DAS), Parent Problem Checklist (PPCL), Relationship Quality Index (RQI) and Life Events. The main goal of this project is to detect novel and reliable markers to be used for risk prediction of psychoses in children, adolescents and young adults. This project is supported by a grant from the Italian Ministry of Health (Project title: 'SPES Service for detection of Pre-psychosES: from gene-environment interactions to phenomenology'). Within the same line of research, the relationships between psychotic and obsessive symptoms in young adult twins (Fagnani et al., 2011) and between magical ideation and personality in adult twins (Brambilla et al., 2014) were investigated.

Within a collaboration with the Social and Cognitive Neuroscience Laboratory of the Sapienza University in Rome, whose main research interest is the neural representation of body image in healthy and brain-damaged patients, the ability of monozygotic (MZ) twins to distinguish their own face from the face of their co-twins was examined. Self-face recognition is, in fact, crucial for the sense of identity and for building and maintaining self-awareness. Results showed that twins lack the typical self-face advantage in recognizing their own face over other, very familiar faces. Moreover, this lack of self-face advantage was negatively predicted by how much they felt physically similar to their co-twins as well as by specific personality traits, such as anxious or avoidant attachment style (Martini et al., 2015).

As regards ITR research on prosociality, we considered the central role of empathy in prosocial behavior and human cooperation. So far, very few twin studies have investigated innate and environmental effects in adult empathy and, even fewer have investigated possible gender differences in these effects. A twin study (Toccaceli et al., 2018) was conducted to examine innate and environmental influences on three components (cognitive, emotional and social skills) of an empathy scale frequently used with adults, the Empathy Quotient by Baron-Cohen \& Wheelwright (2004), and to explore gender differences in these influences. Women's empathy (and its subdimensions as well) seemed to be predominantly driven by genetic factors and individual (non-shared) experiences, whereas for males, no genetic contribution and substantial influences of both shared and individual environmental effects emerged. Age did not moderate empathy heritability in adulthood.
Only for the social skills dimension, genetic and environmental proportions of variance were similar for men and women. The study suggested possible gender-specific innate and environmental influences on empathy and its cognitive and emotional components that need to be confirmed in future studies.

Most previous research on attitude to participate in research and biobanking is focused on disease-oriented biobanks, while healthy donors' motivation was scarcely explored. To contribute to fill this gap, traits such as 'willingness to donate' and 'attitudes' toward biological samples donation for research were investigated by a mail survey conducted in 2012 among a large sample of twins $(N=4894$; age range: $18-65)$ enrolled in the ITR who had not yet donated for research (Toccaceli et al., 2014). More than $80 \%$ of respondents expressed willingness to donate. A prevailing cooperative attitude to donation emerged. Individual social and cultural features were likely to influence the attitude to donate. Education emerged as an important factor shaping these traits.

Moreover, a convenient sample of ITR twins aged 50 years and older is currently being involved in a qualitative research on the issue of 'brain post-mortem donation for research.' The study is conducted within the framework of a larger project focused on the molecular basis of Frailty (Project leader: University of Milan - Cariplo Foundation, Call 2016); as a secondary objective, it aims to compare the attitude to 'research participation' and 'biobanking donation' between twin and non-twin populations.

\section{DNA Damage and Metabolism}

The role of genes and environment in the response to oxidative stress and in the metal blood levels was studied in 95 adult twin pairs (64 MZ and 31 dizygotic [DZ]). Results showed that the variance of non-enzymatic antioxidant capacity, and of the activity of the enzyme that removes oxidatively damaged guanine bases (8-oxoguanine DNA glycosylase, OGG1) is explained by environmental factors only, which include toxic metals such as $\mathrm{Pb}, \mathrm{Cd}, \mathrm{Al}$, Mn and Ni (Medda et al., 2016).

We are also investigating the relationship between overweight/ obesity and DNA damage response; to this aim, we enrolled $15 \mathrm{MZ}$ pairs discordant for body mass index, and we collected blood, buccal wash, urine and feces before and after weight loss of the heavier twin due to hypocaloric diet.

\section{Atherosclerosis, Wellbeing and Stress}

Over the past years, the ITR dedicated most of its efforts to improve knowledge on the etiology of atherosclerosis. A total of 380 adult twin pairs (230 MZ and $150 \mathrm{DZ}$ pairs) with a mean age of 49.1 years (age range 18-82) were recruited for the 'International Twin Study 2009'. Anthropometric measurements, atherosclerotic 
signals (such as intima media thickness [IMT], femoral and carotid plaques presence and composition, systolic and diastolic blood pressure, flow velocity, Augmentation Index and pulse wave velocity $[\mathrm{PWV}]$ ) and psychological wellbeing profiles were collected from the twins participating in Italy, Hungary and the USA in 2009. Moreover, an Italian subsample underwent a follow-up examination in 2014 (Pucci et al., 2018). Almost all of the Italian twins (96.8\%) had donated a saliva sample at the beginning of the study. Such a well-characterized population allowed us to establish that genetic influences are particularly relevant for plaques development in carotid and femoral arteries (heritability: 68\%-78\%; Fejer et al., 2017; Tarnoki et al., 2012), while distensibility and IMT seem to be largely influenced by unique environmental factors (E: 60\%-70\%). Regarding arterial stiffness and blood pressure measurements, our findings highlighted that genetic and environmental influences contributed equally to the observed variability. Furthermore, the role of shared environment was found to be negligible for most of the studied traits, as expected considering the mean age of participants (Medda et al., 2014).

More recently, ITR research interests were oriented toward investigations on the link between behavioral characteristics and biological parameters, a field in which a lot of work remains to be done. In this respect, the association between personality traits and atherosclerosis risk is currently under study on the same sample of twins aged 18-70 years that had been thoroughly assessed for atherosclerotic markers. Personality evaluation was based on the Five Factor Model as measured by the Short Adjectives Checklist of Big Five (Perugini \& Leone, 1996). Preliminary results showed a significant positive association between 'Openness to experience' and arterial stiffness (as measured by PWV), not only in twins as individual subjects but also in the MZ intra-pair analysis that allows for control of genetic and shared environmental confounding factors.

A further study has recently been set up by the ITR with the aim of investigating sclerosis and stenosis of the aortic valve. Fifty MZ and fifty DZ twin pairs will be evaluated in collaboration with the clinical research hospital Monzino Cardiology Centre, which exclusively specializes in cardiovascular diseases. According to the study protocol, all subjects will undergo echocardiographic and carotid ultrasonographic assessments and will complete several questionnaires to measure their levels of chronic stress. The enrollment of twins for this study is still ongoing.

\section{Other Ongoing Studies}

A special interest of the ITR researchers is also placed on autoimmune diseases, metabolic disorders and chronic pain. The project 'Biomarkers for psoriasis and psoriatic arthritis' aims to study the clinical and biological aspects of twins affected by psoriasis and psoriatic arthritis (PsA) and of their co-twins with or without the disease. In detail, the project will identify novel biomarkers of PsA and will explore the mechanisms of $\mathrm{T}$ and $\mathrm{B}$ cell responses during disease onset; moreover, the project aims to investigate the level of chronic stress experienced by the twins and the efficiency of the adaptive response to stressors. This study is based on MZ twins.

Congenital hypothyroidism $(\mathrm{CH})$ is the commonest treatable cause of mental retardation, but its etiology is not yet fully understood. In 2007, Olivieri and colleagues showed a higher frequency of twins in the $\mathrm{CH}$ population compared to the general population (Olivieri et al., 2007). Currently, two pilot studies using the updated twin sample are ongoing to estimate the siblings' recurrence risk for $\mathrm{CH}$ and to evaluate the importance of genetic and environmental influences on the development of this condition.
Chronic pain $(\mathrm{CP})$ - not related to cancer - is an important phenotype gathering growing attention in public health as well as in genetic epidemiology research (Burri et al., 2018). The ITR started a new twin study on $\mathrm{CP}$ in an adult population, using a brief validated self-administered questionnaire designed to explore occurrence, intensity, causal pathways, use of drugs/treatments and perceived efficacy; furthermore, the relationship of $\mathrm{CP}$ with other phenotypes such as stress and wellbeing components will be investigated. For this study, the ITR is trying to build a joint effort at EU level (with Spain among the first who offered their partnership) to highlight possible country-specific features of $\mathrm{CP}$, including heterogeneity in gene-environment architecture of this trait.

Recently, for a subsample of enrolled twins, GPS coordinates (latitude and longitude) were determined from their home addresses. Using different models, we are able to estimate retrospectively for each twin the exposure to fine particles (PM2.5 and PM10) and nitrogen dioxide $\left(\mathrm{NO}_{2}\right)$, as well as to define the percentage of residential green and blue spaces they lived in. The aim of this new research is to evaluate the effects of natural outdoor environments on different phenotypes and to explore the mediating role of these exposures.

Recently, two new record linkage studies between the ITR and other databases have been set up. The first study will be carried out in collaboration with the Italian Social Security Institute (INPS). The aim of the study is to estimate the heritability of income and other related socio-economic features in different Italian regions. To this end, using procedures that adhere to the recently approved EU privacy law, the ITR database will be linked with the social security database in order to reconstruct the working history of the adult twins enrolled in the ITR. The study has public health implications given that differences in socio-economic status (of which income is one of the measures) reflect differences in health. Depending on the results, different policies could be implemented to reduce those differences.

Furthermore, in the framework of methodological research, considering that the generalizability of twin studies' results is somewhat disputed, the ITR is conducting a new study to verify this assumption in a specific domain. In detail, the objective is to compare pharmaceutical prescriptions and hospitalization between twins and singletons. All the information is retrieved through record linkage - using pseudoanonymized codes between data on twins who live in one Italian region, the regional official health monitoring database for drug expenses reimbursement of the National Health Service, as well as the hospital discharge database. For each twin, three singletons - matched on age, gender and general practitioner - are randomly selected. Data analysis is still ongoing and the final results will be available in the coming months. Variables considered in the comparisons include pharmaceutical categories such as daily doses and duration of the prescription, as well as duration and regime of hospitalization, primary and secondary diagnosis, and surgical or medical procedures.

\section{Dissemination and Education for Citizens}

In its national context, the ITR has been deeply involved in encouraging the growth of the Citizen Science approach advocated by the European Commission, supporting and organizing activities directed to enhance the participation of the general public in scientific processes. Since 2017, we conducted a series of initiatives aimed to involve the junior high school students in designing and performing small twin population surveys within their local communities, using the twin study approach as a scientific research 
method. This experiment was performed on the last European Researchers' Night in 2018; during this event, arranged annually at the end of September for more than 10 years so far, students and citizens in general are brought closer to the various aspects of scientific research.

All the ITR's initiatives are constantly promoted on the ITR social media - Facebook and Instagram - where a strong community of twins and their family members share opinions, sentiments and suggestions for the activities and performance of 'our' and 'their' twin registry.

In 2017, the ITR was awarded with the IgNobel Prize, a parody of the Nobel Prize that is awarded every autumn in Boston (USA) to celebrate 10 unusual achievements in scientific research that 'first make people laugh, and then make them think'; the ITR received the prize for the research on facial recognition (Martini et al., 2015) previously mentioned. The news of the prize was well reported by the Italian broadcast and social media, with a positive 'side effect' in terms of peaks of twin compliance to ITR enrollment during autumn. These fun initiatives should not be under-evaluated as they significantly contribute to get people interested in science.

\section{Ethical and Privacy Issues}

The ITR has always considered the sector of ethics and privacy as one of the tenets of its activities, and it has been in the forefront of ethics in research for more than a decade.

Before addressing this ITR research topic, it is important to highlight that the General Data Protection Regulation (GDPR), agreed on by the European Parliament and Council in April 2016, has significantly impacted on all ITR activities. It has become necessary to revise contents and legal references in the informed consent templates used for ITR enrollments and for specific studies. The GDPR modified the juridical bases of the personal data treatment for research compared to those provided by the Italian law (Legislative decree 196/2003), converging mainly on the basis provided by informed consent (IC) itself. Therefore, ITR experts reviewed the IC and introduced a further key element of consent. It is requested the twins' consent for 'future use of their personal data (provided at enrolment in the ITR or in specific studies) for joint projects agreed on by national and/or international partners, approved by the competent Ethics Boards and addressing objectives or health research sectors related to the ones for which the IC was firstly obtained.' Though the Italian Authority for Data Protection does not encourage its use, this kind of consent has to be considered as a fundamental element especially in the framework of the fast development of data sharing, to avoid possible halts in the health research activities. Considering this last issue, formal procedures were also revised to favor record linkage studies. We are confident that a new deontological code, in the near future, will formally restore a balance between the respect of the autonomy and free participation of individuals on one hand, and the value of research performed for public health purposes on the other hand.

Finally, we consider worth addressing a few results of research conducted by the ITR on this topic during the last few years. When Europe was just preparing to introduce the new regulation on privacy, we conducted a survey among 1700 twins regarding preferences about the access and use of their medical records for public health research without explicit informed consent (Toccaceli et al., 2015). A great majority of respondents refused or was doubtful about the access and use of hospital discharge records or clinical data without their explicit consent. Young and female individuals represented this prevailing profile.
Moreover, for what concerns the informative need of potential biobanks donors among Italian twins, the need for 'tailored' biobanking procedures emerged in a cross-sectional survey about opinions and preferences of healthy twins (Toccaceli et al., 2016). Almost $95 \%$ of participants considered privacy protection an important issue. Higher education was associated with greater concern about type and amount of involvement in biobanking activities; minor concerns were observed for place and duration of specimens' storage, or for presence of benefits for participants. Women were more demanding than men in terms of information they require before deciding to donate.

Highlighting individuals' concerns and preferences about privacy and informed consent for the use of sensitive data can contribute to the design of more effective procedures aiming to maximize research profit from biomedical data and, more importantly, to create an effective system for the protection of personal data tailored to the needs of different people.

\section{Future Directions}

Over the last 20 years, the ITR has developed important research skills and enrollment abilities, and it is now ready to give a further contribution to public health improvements. In particular, it is well equipped to deal with two specific public health duties: surveillance and monitoring of health and behavior of the Italian general population.

The first steps toward this new challenge were recently taken during a brainstorming with a few regional epidemiological observatories, considering the wealth of health information that might derive from the monitoring of a 'sentinel population' made up of regional subsamples of ITR-enrolled twins. The recent introduction of the European GDPR, which implied reviewing and modifying the ITR informative note and consent, represented a special occasion to make twins conscious of the potential role they could play — as a subsample of the general population — if their health administrative data could be merged with the results of specific ITR studies they will participate in. Moreover, the geolocalization, already in place for specific subsamples of enrolled twins, could make it possible to refine various environmental macro socio-economic estimates, thus enriching an 'exposure matrix' to be considered as a proxy of the general population exposures. The ongoing effort of the ITR to strengthen the general value of twin studies is particularly important in this line of research.

Acknowledgments. We are really grateful to all the adult and children twins, and indeed their parents, who have been enthusiastically collaborating with the Registry since its inception.

Conflict of interest. None.

\section{References}

Baron-Cohen, S., \& Wheelwright, S. (2004). The Empathy Quotient: An investigation of adults with Asperger syndrome or high functioning autism, and normal sex differences. Journal of Autism and Developmental Disorders, 34, 163-175.

Brambilla, P., Fagnani, C., Cecchetto, F., Medda, E., Bellani, M., Salemi, M., Stazi, M. A. (2014). Genetic and environmental bases of the interplay between magical ideation and personality. Psychiatry Research, 215, 453-459.

Brescianini, S., Alviti, S., Arnofi, A., Nisticò, L., \& Stazi, M. A. (2017). Growth in early childhood and wheezing at three years: Nature or nurture? Twin Research and Human Genetics, 20, 593.

Brescianini, S., Fagnani, C., Toccaceli, V., Medda, E., Nisticò, L., D'Ippolito, C., . Stazi, M. A. (2013). An update on the Italian Twin Register: Advances in 
cohort recruitment, project building and network development. Twin Research and Human Genetics, 16, 190-196.

Burri, A., Ogata, S., Rice, D., \& Williams, F. M. K. (2018). Twelve-year follow-up of chronic pain in twins: Changes in environmental and genetic influence over time. European Journal of Pain, 22, 1439-1447.

Carter, A. M., Cymbalista, C. M., Spector, T. D., Grant, P. J., \& EuroCLOT Investigators. (2007). Heritability of clot formation, morphology, and lysis: The EuroCLOT study. Arteriosclerosis, Thrombosis, and Vascular Biology, 27, 2783-2789.

Fagnani, C., Bellani, M., Tansella, M., Balestrieri, M., Toccaceli, V., Patriarca, V., ... Brambilla, P. (2011). Investigation of shared genetic effects for psychotic and obsessive symptoms in young adult twins. Psychiatry Research, 188, 276-282.

Fagnani, C., Brescianini, S., Cotichini, R., D'Ippolito, C., Dukic, T., Giannantonio, L., ... Stazi, M. A. (2006). The Italian Twin Register: New cohorts and tools, current projects and future perspectives of a developing resource. Twin Research and Human Genetics, 9, 799-805.

Fagnani, C., Medda, E., Alessandri, G., Delfino, D., D’Ippolito, C., Eisenberg, N., \& Stazi, M. A. (2017). The genetic architecture of effortful control and its interplay with psychological adjustment in adolescence. Journal of Research in Personality, 68, 5-14

Fejer, B., Tarnoki, A. D., Tarnoki, D. L., Lucatelli, P., Littvay, L., Maurovich-Horvat, P., ... Medda, E. (2017). Heritability of the femoral intima media thickness. European Journal of Internal Medicine, $41,44-48$

Goldsmith, H. H. (1991). A zygosity questionnaire for young twins: A research note. Behavior Genetics, 21, 257-269

Greco, L., Romino, R., Coto, I., Di Cosmo, N., Percopo, S., Maglio, M., ... Stazi, M. A. (2002). The first large population-based twin study of coeliac disease. Gut, 50, 624-628.

Kyvik, K. O., Green, A., \& Beck-Nielsen, H. (1995). The new Danish Twin Register: Establishment and analysis of twinning rates. International Journal of Epidemiology, 24, 589-596.

Martini, M., Bufalari, I., Stazi, M. A., \& Aglioti, S. M. (2015). Is that me or my twin? Lack of self-face recognition advantage in identical twins. PLoS One, 10, e0120900.

Medda, E., Fagnani, C., Schillaci, G., Tarnoki, A. D., Tarnoki, D. L., Baracchini, C., ... Stazi, M. A. (2014). Heritability of arterial stiffness and carotid intima-media thickness: an Italian twin study. Nutrition, Metabolism and Cardiovascular Diseases, 24, 511-517.

Medda, E., Minoprio, A., Nisticò, L., Bocca, B., Simonelli, V., D'Errico, M., ... Dogliotti, E. (2016). The response to oxidative stress and metallomics analysis in a twin study: The role of the environment. Free Radical Biology and Medicine, 97, 236-243.

Nebel, A., \& Schreiber, S. (2004). GEHA-the pan-European 'Genetics of Healthy Aging' project. Science of Aging Knowledge Environment, 26, pe23.

Nisticò, L., Iafusco, D., Galderisi, A., Fagnani, C., Cotichini, R., Toccaceli, V., ... Study Group on Diabetes of the Italian Society of Pediatric Endocrinology and Diabetology. (2012). Emerging effects of early environmental factors over genetic background for type 1 diabetes susceptibility:
Evidence from a nationwide Italian twin study. The Journal of Clinical Endocrinology \& Metabolism, 97, E1483-E1491.

Olivieri, A., Medda, E., De Angelis, S., Valensise, H., De Felice, M., Fazzini, C., ... Stazi M. A. (2007). Study Group for Congenital Hypothyroidism. High risk of congenital hypothyroidism in multiple pregnancies. The Journal of Clinical Endocrinology and Metabolism, 92, 3141-3147.

Peltonen, L. (2003). GenomEUtwin: A strategy to identify genetic influences on health and disease. Twin Research, 6, 354-360.

Perugini, M., \& Leone, L. (1996). Construction and Validation of a Short Adjectives Checklist to Measure Big Five (SACBIF). European Journal of Psychological Assessment, 12, 33-42.

Pucci, G., Tarnoki, A. D., Medda, E., Tarnoki, D. L., Littvay, L., Maurovich-Horvat, P., . . Stazi, M. A. (2018). Genetic and environmental determinants of longitudinal stability of arterial stiffness and wave reflection: A twin study. Journal of Hypertension, 36, 2316-2323.

Ristori, G., Cannoni, S., Stazi, M. A., Vanacore, N., Cotichini, R., Alfò, M., ... Salvetti, M. (2006). Multiple sclerosis in twins from continental Italy and Sardinia: A nationwide study. Annals of Neurology, 59, 27-34.

Silventoinen, K., Jelenkovic, A., Sund, R., Honda, C., Aaltonen, S., Yokoyama, Y., \& Kaprio, J. (2015). The CODATwins Project: The cohort description of Collaborative Project of Development of Anthropometrical Measures in Twins to Study Macro-Environmental Variation in Genetic and Environmental Effects on Anthropometric Traits. Twin Research and Human Genetics, 18, 348-360.

Stazi, M. A., Cotichini, R., Patriarca, V., Brescianini, S., Fagnani, C., D'Ippolito, C., ... Salvetti, M. (2002). The Italian twin project: From the personal identification number to a national twin registry. Twin Research, 5, 382-386.

Tarnoki, A. D., Baracchini, C., Tarnoki, D. L., Lucatelli, P., Boatta, E., Zini, C., ... Schillaci G. (2012). Evidence for a strong genetic influence on carotid plaque characteristics: An international twin study. Stroke, 43, 3168-3172.

Toccaceli, V., Brescianini, S., Fagnani, C., Gigantesco, A., D’Abramo, F., \& Stazi, M. A. (2016). What potential donors in research biobanking want to know: A large population study of the Italian Twin Registry. Biopreservation and Biobanking, 14, 456-463.

Toccaceli, V., Fagnani, C., Eisenberg, N., Alessandri, G., Vitale, A., \& Stazi, M. A. (2018). Adult empathy: Possible gender differences in gene-environment architecture for cognitive and emotional components in a large Italian twin sample. Twin Research and Human Genetics, 21, 214-226.

Toccaceli, V., Fagnani, C., Gigantesco, A., Brescianini, S., D’Ippolito, C., \& Stazi, M. A. (2014). Attitudes and willingness to donate biological samples for research among potential donors in the Italian Twin Register. Journal of Empirical Research on Human Research Ethics, 9, 39-47.

Toccaceli, V., Fagnani, C., \& Stazi, M. A. (2015). Medical records confidentiality and public health research: two values at stake? An Italian survey focus on individual preferences. Journal of Public Health Research, 4, 401.

Violani, C., Devoto, A., Lucidi, F., Lombardo, C., \& Russo, P. M. (2004). Validity of a short insomnia questionnaire: The SDQ. Brain Research Bulletin, 63, 415-421. 